\title{
DIE VERBAND TUSSEN KUNS EN KERK
}

\section{N O ROOS}

Die verband tussen kerk en kuns strek oor baie eeue en is steeds van aktuele belang. Vanweë die noue verband wat tussen godsdienstige en die estetiese ervaring bestaan, is dit aanvaarbaar dat die kerk van tyd tot tyd standpunt sal inneem oor die aard en funksie van die kunste, en eweneens aanvaarbaar dat die kunste soms rigtings sal inslaan wat skynbaar in stryd is met die strewes en standpunte van die Christelike kerk.

Die verhouding tussen kerk en kuns is juis vanweë die sterk ooreenkomste tussen hulle, uiters gevoelig. Ons kan sê dat die kerk deur sy verkondiging van die evangelie, en kuns deur sy uitdra van begrippe van skoonheid, albei die positiewe opheffing van die mens ten doel het. Albei streef deur hul onderskeie bemoeienisse met die mens en sy wêreld, daarna om die wêreld te verbeter en daardeur die geestelike milieu te skep waarin die mens se geestelike behoeftes en strewes bevredig kan word.

Godsdiens, soos kuns, is uitsluitlik op die mens, en meer bepaald op die gees van die mens gerig. Albei het te make met die vervulling van 'n geestelike behoefte van die mens. In die proses staan godsdiens en kuns aanvullend tot mekaar, en kan die een nie die ander vervang nie.

Estetiese genot en religieuse aanbidding het bepaalde psigologiese ooreenkomste in soverre albei die emosionele en geestelike moontlikhede van die mens betrek, die verbeeldingswêreld aangryp en toestande van bewondering, verheerliking en verwondering ontsluit. Hierdeur word 'n gevoel van harmonie en genoegdoening, ' $n$ welbehae by die mens opgewek en wat hy graag in homself wil laat voortduur. Beide godsdiens en kuns is 'n soeke na 'n diepere waarheid waardeur ons gelei word na 'n groter en suiwerder insig in die realiteit.

Alhoewel bogenoemde punte van ooreenkoms tussen godsdiens en kuns wel bestaan, is daar ook punte van verskil wat uitgewys kan word. Die belangrikste verskil is moontlik geleë in die fisiese konkreetheid van die estetiese objek, teenoor die abstrakte kwaliteit van die godsdienstige objek.

Verder is dit so dat godsdiens morele vereistes stel aan die mens in sy daaglikse, aardse bestaan, terwyl die estetiese genot verwyderd bly van morele en praktiese probleme. Waar godsdiens die mens in sy totaliteit, dus ook in sy eindbestemming raak, is en bly kuns slegs ' $n$ onmiddellike bevrediging van die mens se estetiese behoeftes. 
Waar kuns ons wêreld in verbeeldingsterme wil verander en verbeter, poog godsdiens om dit in aktuele terme te vermag. Hoe dit ookal sy, godsdiens was en ek glo is steeds die kragtigste bron van inspirasie vir die kunste.

Daarom ook dat beweer word dat godsdiens die moeder van die kunste is. Daar ontstaan egter gewis probleme indien godsdiens voorskrywend sou wou optree vir die kunste - of andersom.

Vanaf die vroeg-christelike periode tot en met die Renaissance, het die beeldende kunste in 'n dienende posisie tot godsdiens gestaan.

Die kerk as opdraggewer het die visuele kuns aangewend om die Bybelse verhaal oor te dra aan 'n grootliks ongeletterde publiek.

In die proses het die kerk nie net die tematologiese inhoud van die kunswerk bepaal nie, maar inderdaad ook die houding van figure, kleredrag en kleurgebruik van die kunstenaar uitvoerig voorgeskryf. Die kunstenaar was in werklikheid slegs die uitvoerende instrument in die hande van die kerk en sy amptenare.

Dit is die kerk, en nie die kunstenaar nie wat die Christelike ikonografie bepaal het. Die hele wye simboliek wat die visuele kunste aanwend om die Christelike geloof te verbeeld, is inderdaad die skepping van die kerk en die kerkvaders.

As Thomas van Aquino dus uitsprake lewer oor die kuns, en as voorskrif bepaal dat die kunstenaar moet streef na Perfeksie, bedoelende die nastreef van die volkome geïdealiseerde natuurvorm, en na Proporsie, bedoelende die regte harmonie en juiste verhouding volgens natuurlike maatstaf van alle onderdele binne die kunswerk as geheel en Claritas, bedoelende klaarheid in die sin van helderheid, duidelikheid, suiwerheid en verstaanbaarheid van vorm en voorstelling in die geheel as eenheid, is dit meer direk as riglyne vir die opdraggewer as vir die uitvoerder, naamlik die kunstenaar, bedoel.

Terwyl die kuns in hierdie strenge onderdanige posisie verkeer, kom dit voor asof kerk en kuns vreedsaam naas mekaar kan bestaan. Namate 'n steeds toenemende versekularisering plaasvind, en die kunste uiteindelik ook daarin en daardeur aangeraak word, ontstaan 'n gaping tussen kerk en kuns wat tot in ons tyd voortduur.

Die 13de en 14de eeu is aan die eenkant nog ' $n$ voortsetting van die Middeleeue, maar aan die anderkant reeds die inleiding tot 'n nuwe tydsgewrig, die Renaissance. Langs die Middeleeuse mens met sy transendente lewensopvatting wat veral neerkom op sy verhouding tot God en die hiernamaals, kom die nuwe Renaissance Christenmens na vore, met sy sterker bewussyn van sy omgewing en die wêreld waarin hy lewe. 'n Tydperk waarin die mens en die natuur op wetenskaplike wyse ondersoek sou word, het aangebreek. Ook die kunstenaar, ofskoon hy nog 
met een voet in die Middeleeue staan, word deur die nuwe tydsgees geraak, met die gevolg dat sy kuns 'n steeds sterkerwordende individualiteit en eiesoortige natuurwaarneming begin vertoon. Die werke van die groot meesters van die Renaissance, Michelangelo, Leonardo en Titiaan, alhoewel daarin nog steeds deurlopend 'n godsdienstige piëteit bestaan, reik ook uit na die vrye eksperimentering. Aan die een kant sluit hulle werke aan by die Aristoteliese gedagte en die standpunt van Thomas van Aquino, aan die ander kant word hul werk gekenmerk deur steeds toenemende vrye ontdekking en uitvinding. Wiskundige perspektief, proporsie en komposisieleer, en die anatomie, is terreine wat op wetenskaplike basis deur kunstenaars bestudeer word. Trouens, Leonardo gaan sover om te beweer dat kuns as wetenskap selfs as eksakte wetenskap op empiriese wyse beoefen moet word.

Leonardo, terwyl hy die kunste koppel aan die natuurwetenskap, stel dit ook gelyk aan die wysbegeerte, wat hom met dieselfde dinge as die kunste besig hou, $\mathrm{nl}$ nie slegs met die uiterlike, maar veral met die innerlike eienskappe van die natuur, ook die menslike-natuur. Daarom ook stel hy die kunstenaar hoër as die ambagsman - is hy die heer van alle geskape dinge en word die werk van die Ewige Skepper in hom voortgesit. Dit is 'n standpunt wat aansluit by dié uitgewerk deur Thomas van Aquino.

Michelangelo is minder filosofies as Leonardo ingestel, maar ook hy is ' $n$ denker. Dit is opvallend hoe suiwer en diep die groot meesters van die Renaissance hul kuns deurdink het. Uit sy uitlatings oor sy kuns, kan afgelei word hoe diep godsdienstig Michelangelo was en hoe hy sy kuns as wyse van vereniging met God gesien het.

Ook hy staan na aan die opvattings van Aristoteles aan die een kant en Thomas van Aquino aan die ander kant. Hy is ook gesteld op die getroue afbeelding van die natuur. Soos hy dit stel: Om een van hierdie dinge (uit die natuur) volmaak na sy aard na te boots (imitae), beteken in my oë niks minder of meer dan die skeppingsdaad van die Ewige Skepper na te doen nie.

Aan die ander kant aanvaar hy die vermoë van die kunstenaar om verbeeldingryk te werk te gaan, om te ontdek en uit te vind. Die taak van die kunstenaar is nie bloot om ' $n$ akkurate afskynsel van die natuur te gee nie; hy het die vryheid om dit wat hy nooit gesien het deur verbeelding op te roep - maar hy mag nie dit uitbeeld deur sy verbeelding, wat nie in die werklikheid van die gegewe goddelike skepping sou kon bestaan nie. Die Renaissance plaas die kunste onherroeplik op 'n eie selfstandige ontwikkelingspad.

Namate ons voortgaan deur die eeue sien ons hoe die kunste en aspekte daarvan as selfstandige dissipline nagevors word. Terwyl 
kwessies soos die rol van die gevoei en die rede in die kunswerk, die verbeeldingskrag en ekspressievermoë van die kunstenaar, die probleme van empatie, seleksie en waarneming onder die loep geneem word, en die nuwe wysgerige rigting van die estetiek deur Baumgarten gegrondves word, bly die ou Aristoteliese en Platoniese vraagstukke van benadering en ontwyking van die natuur steeds die deurlopende problematiek in die beeldende kunste. Tussen die twee pole speel die beeldende kunste hom af, soos dit steeds nog gebeur.

Tematologies verdeel die Beeldende kunste met die koms van Protestantisme in twee: Die Roomse wêreld wat in tema en motief hoofsaaklik nog vashou aan die religieuse; teenoor die Protestantse wêreld wat in toenemende mate begin wegbeweeg van die godsdienstige tema, soos blyk uit die 18de eeuse Nederlandse kuns. Tog keer die groot figure in die Protestantse kuns steeds terug na die Bybelse verhaal en word die grootste en ontroerendste werke met godsdienstige inslag juis deur hulle gelewer. Die werk van Rembrandt is hiervan 'n voorbeeld. Namate ons egter nader aan ons eie tyd beweeg, neem die versekularisering van die kunste steeds toe - en word die uitdruklik godsdienstige motief soos dit vroeër bestaan het meer en meer op die agtergrond geskuif.

Die mens en sy problematiese aardse bestaan, en selfs mundane onderwerpe soos die stillewe en landskap tree al meer op die voorgrond as temas en motiewe waarmee die kunstenaar hom besig hou. Teen die helfte van die 19de eeu met die koms van die sogenaamde Impressionisme, word die grondslae gelê vir die radikale en selfs revolusionêre weë wat die beeldende kunste in die 20ste eeu inslaan.

Die problematiek van ons eeu is aan ons almal welbekend. Die teorieë van Einstein, Freud en Marx het die verloop van hierdie eeu ingrypend geraak. Die hoogtes waartoe ons op tegnologiese gebied en algemene vernuf gevoer is, is selfs dikwels nie vir ons ewe begryplik nie. Aan die een kant wil ons na die sterre gryp en styg ons uit na byna bomenslike hoogtes; aan die ander kant skep ons die grootste en swartste absesse menslik denkbaar. Dit spreek vanself dat die kunste nie onaangeraak kan bly deur hierdie radikale veranderde omstandighede nie. So ook nie die godsdiens nie. Albei is immers gemoeid met die menslike gees en geestelike welvaart.

Kuns as spieëlbeeld van sy tyd moet hierdie nuwe tendense reflekteer - en as kuns, soos dikwels beweer word, in ' $n$ krisis verkeer, is dit inderdaad ook so dat die westerse mens en sy beskawing hom in ' $n$ krisistyd bevind.

Om al die faktore wat op die kunste ingewerk het, en dit in wese en aard ingrypend verander het, hier te bespreek is onmoontlik. Laat ons 
volstaan deur te sê dat die een uitstaande gebeurtenis sover dit die kuns betref, die bevraagtekening en breuk met die ou tradisionele waardes en norme van die kuns was. Die "hersiene waardes" en strewes wat die kuns vir homself geskep het, het 'n belangstelling in ander beskawings meegebring wat bestudeer is en waaruit nuwe gedagtestrominge en vitaliteit vir die kunste geput is. Alhoewel dit die kunste verbreed en met nuwe lewe en energie gelaai het, het dit tog die groot stroom van kontinuïteit verbreek en nuwe bane na die onbekende geopen. Die kunstenaars van die 20 ste eeu wou terugkeer na 'n nul-punt; as't ware 'n skoon bladsy open. Die begeerte om terug te keer na ' $n$ outentieke kuns het by byna al die leidende figure in die kuns aan die begin van hierdie eeu bestaan. Die rug word gekeer op die sogenaamde intellektuele kuns en die spontane uitdrukking word aangegryp. Die sogenaamde "primitiewe" kuns van Rousseau en ander latere figure word erken en aangehang juis omdat dit die element van ongeskonde naïewe kinderlikheid bevat.

Die kuns het skynbaar finaal gebreek met die standpunt van benadering van die natuur en nader beweeg aan die standpunt van ontwyking van die natuur. Die voorstellende of nabootsende tradisie is finaal oorboord gegooi ten gunste van 'n kuns wat in die subjektiewe gedagtewêreld van die mens setel.

Dit wil voorkom asof die laat 19de eeuse slagspreuk van L'Art pour L'Art tesame met 'n sug na individualisme en self-ekspressie by die kunstenaars self, asook ' $n$ doelbewuste verbreking van die tradisionele bande van die verlede en 'n soeke na nuwe lewensgewende inspuitings uit ander kulture, die kuns van ons tyd finaal in ander bane gelei het. Waar die kunstenaar van vroeër vanuit homself, verwyderd en objektief sy wêreld bekyk en interpreteer, weerspieël die nuwe kunstenaar sy eie subjektiewe reaksies op daardie wêreld in sy kuns.

Dit is duidelik dat met hierdie wending in kunsbenadering, nie net gebreek is met die tradisionele vormtaal elemente nie, maar dat baie van die ou opvattinge oor die "skoonheidsbegrip" en ander teorie wat rondom die kunswerk geformuleer is, nie verder geldig kon bly nie.

Om hierdie wendinge te kan begryp, vereis ' $n$ heel nuwe ingesteldheid by ons as toeskouers. Die komplekse aard van ons kuns vereis noukeurige nadenke en insig, nie alleenlik in kuns nie, maar in alle fasette van ons moderne wêreld, want kuns staan immers nie geïsoleerd in ons wêreld nie. Om hierdie kunsuitinge ligtelik, simplisties vanuit 'n enkele hoek te bekyk, en te beoordeel, soos sommige skrywers dit wel wil doen, is nie net onmoontlik nie, maar enigsins naïef. Die skrywer Rookmaker wat met sy boek, Modern Art and Death of a Culture ook in ons land opslae gemaak het en in wye kringe aanvaarding gevind het, maak hom hieraan skuldig. 
Dit is natuurlik so dat die sogenaamde moderne kuns uit verskillende hoeke met agterdog bejeën word. Om verskeie redes is dit heeltemal begryplik - veral vanweë die feit dat die kunswerk wat losstaan van die uitbeelding van die herkenbare natuur, 'n gevoel van onsekerheid by die toeskouer mag opwek. Onsekerheid is juis ' $n$ toestand wat 'n gesonde teelaarde vir agterdog skep.

Verder is dit verstaanbaar dat, waar die kunstenaar hom nog wend tot die kenbare en hy terwille van òf suiwer vorminhoudelike redes òf terwille van ekspressie, die tradisionele vorm of herkenbare vorm verdistorteer, hierdie verskynsel as ò onvermoë ò moedswilligheid of selfs kwaadwilligheid van die kant van die kunstenaar geïnterpreteer word. Tog beskou ons nie dieselfde tendense in die Gotiese kuns in dieselfde lig nie.

Kuns word deur baie mense beskou as 'n lastigheid, soos 'n perdevlieg wat voortdurend aan die lyf van die gevestigde opvattings bly steek. Kuns word deur diegene gesien as iets wat gevaar inhou vir die moraliteit en vir die algemene goeie gang van sake in 'n gemeenskap. Dit gee aan mense vreemde idees en opvattinge, moedig individualisme aan eerder as konformiteit, en ondermyn selfs die aanvaarde norme waarop ons glo 'n goeie gemeenskap berus.

Kuns word derhalwe in wye kringe met groot suspisie bejeën; voorgehou as die werktuig van Marxisme en Kommunisme en 'n bedreiging vir die sedelik-goeie in die gemeenskap. Hierdie verskynsel is egter nie nuut nie, en geensins beperk tot ons houding teenoor die moderne kuns nie.

Plato het reeds in sy Republiek sterk standpunt ingeneem teen die kunste as 'n moreel-ondermynende aktiwiteit. Ook andere soos Leo Tolstoy het hom oor die kwessie van kuns en moraliteit uitgelaat en in sy werk, What is Art (1895) gaan hy sover om alle kuns wat nie die "godsdienstige begrip by die mens bevorder nie" eenvoudig af te skiet. So is daar talle meer voorbeelde van.

Met bogenoemde in gedagte is dit begryplik dat die kerk hom ook hier te lande moet vergewis van sy standpunt oor die kunste.

Die Algemene Sinode van die Ned. Geref. Kerk het dan ook in 1982 die volgende riglyne met betrekking tot dié beskouing oor die Christen en die Kuns aanvaar:

1. In gehoorsaamheid aan die Skeppingsopdrag (Gen. 1:28; 2:15) is die kunstenaar geroepe om sy talente ywerig te beoefen en kunsprodukte tot eer van God en heil van die medemens te lewer.

2. Dit is die roeping van die kunstenaar om die lewenswerklikheid te 
verken, te interpreteer en om met die aanwending van sy besondere talente sy bevindinge te openbaar.

3. Die skerpsinnige waarneming van die begaafde kunstenaar, en sy uitbeelding van die waarheid, dwing bewondering af terwyl dit die ingeskape behoefte aan skoonheid by die mens bevredig.

4. Die ongeregtigheid en die sedeloosheid binne die samelewing mag by geleentheid die kunstenaar dwing om hierdie kwaad te identifiseer sodat ander dissiplines dit kan bestry.

5. Die Bybelskrywers bied aan die kunstenaar die model vir die uitbeelding van die sondige en gebroke werklikheid deurdat die kwaad nie deur die beskrywing daarvan verheerlik word nie. Selfs die seksuele word só diskreet behandel dat verkeerde hartstogte nie opgewek word nie. (Vergelyk Gen. 19:31-36; Gen. 38; Gen. 39; 2 Sam. 11; 2 Sam. 13; Spr. 7; Eseg. 23.)

6. 'n Kunswerk besit nie net estetiese waarde nie - daar is ook maatskaplike, psigologiese, religieuse, etiese, staatkundige en ekonomiese norme wat met die beoordeling van 'n kunswerk meespreek.

7. Die Christen-kunstenaar maak hom nie aan die oorbeklemtoning van die dissonant in die geskonde werklikheid skuldig nie.

8. Die sogenaamde egte, goeie kuns, wat God-onterend is en die heil van die medemens aantas, is ten spyte van sy kunskwaliteite onaanvaarbaar.

9. Die vryheid wat die skeppende kunstenaar geniet, stel hoë eise aan die verantwoordelikheidsin van daardie kunstenaar. Daarom verdien die gemeenskap van owerheidsweë beskerming teen die produkte van onverantwoordelike kunstenaars.

10. Die Kerk betuig besondere waardering teenoor dié kunstenaars wat in die beoefening van hulle gawes die Christelike lewensnorme eerbiedig.

By die deurlees van hierdie riglyne kan daarmee in die algemeen weinig fout gevind word. Wat die kerk hier uitspel is sonder twyfel aanvaarbaar, nie net vir die Christen-kunstenaar nie, maar vir enige kun- 
stenaar wat as gebalanseerde en ernstige mens sy skeppingswerk verrig.

As ons kyk na die uiteenlopende nalatenskap van ons kunstenaars van die verlede en die hede is daar sekerlik weinig ernstige kunswerke wat buite hierdie neergelegde riglyne, as breedopgevatte riglyne, sal val. Die probleem wat hom voordoen met hierdie riglyne, soos trouens met alle riglyne, is in die interpretasie en toepassing daarvan. ' $n$ Wesenskenmerk van die kunswerk is die multidimensionele aard daarvan. Die kunswerk besit dus die vermoë om op verskillende wyses tot verskillende waarnemers te spreek. Hierin lê juis die probleem.

Die kunswerk skep 'n verskeidenheid moontlikhede vir interpretasie: op die konkrete vlak kan die tema wat daarin uitgebeeld word ons aantrek of afstoot. Die tegniese beheer van die kunstenaar kan ons bewondering afdwing of ons koud laat, ons kan die kunswerk as fisiese objek in 'n omgewing aantreklik of onaantreklik vind. Die toeskouer kan egter by hierdie dinge verbykyk en aangegryp word deur vorm en inhoud, elemente soos kleur, ritme, harmonie en eenheid van die stuk. Ons kan ontroer word deur ' $n$ werk ongeag tema of tegniek - dikwels is dit dan ook so dat ons nie in woorde kan uitdruk wat ons ontroer nie. Dit is egter moontlik dat dit wat my ontroer 'n volgende persoon ongeroerd mag laat.

Die kunswerk besit die vermoë om tot ons te spreek; maar spreek nie slegs ' $n$ enkele heldere boodskap nie. Dit bied ons ' $n$ magdom van moontlikhede wat 'n beroep doen op die toeskouer: kennis, gevoelsvermoë, sensitiwiteit, opgevoedheid, en algemene kultuuragtergrond ten einde dit te beleef.

As Shelley beweer dat skoonheid in die oog van die toeskouer lê wys hy daarmee presies op hierdie verskynsel.

Die kunswerk is dus slegs medium vir ons eie gevoelens en lewenshouding. Kuns wat moraliserend didakties optree, kan selde tot groot kuns gereken word. Daarmee gaan ons oor in propagandakuns soos aangetref in Nazi-Duitsland en teenwoordig nog in die USSR.

Die kwessie van die sedelike in die kuns strek dus veel wyer as slegs die verantwoordelikheid van die kunstenaar.

Die kunstenaar kan in sy lewens- en wêreldbeskouing aan die hoogste norme beantwoord; en sy werk kan dit deur en deur uitstraal tog as dieselfde waardes nie voorkom by die toeskouer nie, sal sy boodskap òf geheel verlore gaan, òf soos dikwels gebeur selfs verkeerdelik opgevat word.

Hiervan is daar talle voorbeelde. Andersom kan dit ook gebeur: as die kunswerk bloot op gesigswaarde beoordeel word, $d w s$ in dit wat waarneembaar voorgestel word, kan 'n werk deurgaans as goed en religieus beskou word, terwyl dit in gees en diepere betekenis glad nie die 
geval is nie.

Die treffendste voorbeeld hiervan is seker die kruisiging van Christus soos uitgebeeld deur die ateïs Salvador Dali.

Die beoordeling van kuns stel as voorvereiste, soos vroeër reeds na verwys, kundigheid, sensitiwiteit van gevoel en egtheid by die toeskouer - nie verskillend van 'n preek nie - dieselfde vereistes geld vir die godsdiensbeoefening.

Sonder die besondere kwaliteite kan geen riglyn van hulp wees nie. Die feit is dat daar nie deur een dissipline aan ' $n$ ander voorgeskryf kan word nie, en geen reëls neergelê word wat 'n dissipline soos die skeppende kuns in 'n bepaalde baantjie wil stuur nie. Skepping soos ons dit verstaan in die skeppende kunste, is om orde uit chaos te skep - en totstand te bring wat nog nie voorheen bestaan het nie. Alle kuns het dit in gemeen. Wat ons as vorm beskryf is niks anders as visuele orde nie. In hierdie orde lê skoonheid. Om dit te bereik, moet die kunstenaar vry wees - 'n vry mens is verantwoordelik vir sy eie dade; die werk van 'n slaaf is 'n ander se verantwoordelikheid. Dit is die posisie waarna vroeër verwys is, toe die Christelike kerk direk as opdraggewer vir die kunstenaar opgetree het. Op gesigswaarde geneem, kwalifiseer die werke uit daardie tyd as Christelike kuns - maar slegs so in die imiterende of literêre inhoud daarvan. In gevoel is daardie kuns dikwels objektief en onbetrokke, en juis so omdat die kunstenaar nie vryheid van uitdrukking gehad het nie. Die woord skeppend is gelyk te stel aan vryheid. Dit is hierdie vryheid om skeppend te kan optree wat by uitstek die moderne kuns karakteriseer en waarde daaraan verleen:

Die kunstenaar is die skepper van nuwe objekte - hy is 'n reisiger in die onbekende. Omdat hy onbekende terreine betree, is hy ontdekker en uitvinder, en werp hy deur sy skeppende kunswerk, lig op dit wat vir ons nog verborge was: bring hy totstand wat voorheen nooit bestaan het nie. Omdat hy ontdekker en uitvinder is, 'n reisiger in die onbekende, kan hy nooit vooraf bepaal wat die eindresultaat van sy ontdekking sal wees nie - of dit goed of sleg sal wees nie. Die kunstenaar kan nie vooraf besluit of voorsien wat die eindproduk van sy kuns sal wees nie.

Hy kan hoogstens 'n rigting bepaal waarin sy gedagtes gestuur word. Die gees wat die werk sal uitstraal, hang af van die gees van die kunstenaar. Die boodskap wat die werk sal oordra, hang af van die gees van die toeskouer.

Die ourspreekwoord, waar die hart van vol is, loop die mond van oor - is myns insiens hier van toepassing.

Ons leef in 'n onvolmaakte wêreld en dit word in elke menslike aktiwiteit gereflekteer - ook in die kunste en in. die Christelike godsdiens. 
Nie alles wat in die naam van kuns tot stand gebring word, beantwoord aan ons hoë ideale vir kuns nie. Net so min kan ons alles wat in die naam van godsdiens gepredik word, as die Woord van God aanvaar.

Deur die een te behou en die ander te verbied, volgens ons opvattinge van reg en verkeerd, soos beskou vanuit ' $n$ bepaalde oomblik in tyd en kennis, sou ons wêreld verskraal en ons ontneem van ons grootste verantwoordelikheid: die maak van keuses en neem van besluite. 